\title{
Design Universal sob a ótica dos estudantes e profissionais brasileiros
}

\author{
Universal Design from Brazilian students \\ and professionals' perspective
}

\author{
por Thais de Carvalho Larcher Pinto, Jorge Elias Dolzan e Luiz Salomão Ribas Gomez
}

\section{RESUMO}

0 presente artigo comunica os resultados de um trabalho de conclusão de curso, que abordou a temática do Design Universal (DU). 0 DU tem como ideia atender à maior gama de variações possíveis das características antropométricas e sensoriais das pessoas, encarando a diferença como normalidade a ser respeitada e considerada no desenvolvimento de produtos. Através da revisão bibliográfica foi possível conhecer a origem e o histórico do DU e a aplicação dos seus sete princípios no projeto de produtos. E, a partir da aplicação de um questionário, buscou-se uma noção do nível de conhecimento na área do design sobre essa temática. Os resultados obtidos indicaram um baixo nível de conhecimento desse tema pelos estudantes e profissionais brasileiros, porém, acredita-se que as mudanças decorrentes do aumento da faixa etária da população, e uma maior sensibilização às causas sociais nas últimas décadas poderá, portanto, alterar esse quadro.

Palavras-chave Acessibilidade; Design Universal; Inclusão Social

\section{ABSTRACT}

This article presents the results of a final graduation work, which explains about the Universal Design (UD). The concept of UD is to connect the widest range of possible variations of anthropometric and sensory characteristics of the human being, seeing the difference as something normal and to be respected and considered in the development of a product. Through bibliographic review it was possible to understand the origin and history of UD and the application of its seven principles in product design. And also, With the support of a methodology, a research was conducted, which pointed some important issues for reflection of the current Brazilian scene on the subject. The results and conclusions of this research indicated a low level of knowledge in this field by design students and professionals. the changes resulting from increasing age of the population, and greater awareness to social causes in recent decades may therefore change this picture.

Keywords Accessibility; Universal Design; Social Inclusion 


\section{Introdução}

Este artigo comunica os resultados finais obtidos na monografia Design Universal - Panorama a partir do Design brasileiro. A pesquisa se concentrou em entender o desencadeamento do Design Universal nos Estados Unidos, na Europa e no Brasil, a partir de um estudo de seu histórico, de seus princípios, e dos mais recentes dados sobre leis e normas técnicas brasileiras que contemplam o DU. 0 presente trabalho propõe clarear a temática ainda pouco explorada, e sintetizar os dados levantados no questionário, que foi aplicado com estudantes e profissionais das cinco regiões geográficas brasileiras - norte, nordeste, centro-oeste, sudeste e sul a fim de compreender e contextualizar um panorama atual do Design Universal no Brasil, ou seja, o entendimento por parte dos estudantes e profissionais brasileiros sobre este assunto.

De acordo com o Censo de 2000 do Instituto Brasileiro de Ceografia e Estatística - IBGE, $14,5 \%$ da população total tem algum tipo de incapacidade ou deficiência no Brasil, o que representa um total de 25 milhões de pessoas com dificuldades diárias de interação com o ambiente que nos rodeia. 0 pressuposto de que o homem deve se adaptar aos ambientes, e não ao contrário, evidenciou a exclusão daqueles que não se enquadram no padrão. Ao se idealizar e construir o ambiente da cidade para o homem ideal - padrão estético vitruviano' - acabou-se por colocar em desigualdade uma significativa parcela da população que não se encaixa nesse padrão médio - crianças, idosos, deficientes, entre outros - , ou mesmo, pessoas que estão apenas em condições de deficiência temporária, ou seja, todos, em algum momento da vida.

Há alguns anos, detectou-se que as pessoas que enfrentavam problemas com o ambiente não eram somente aquelas que tinham deficiências. Criou-se então a expressão pessoas com mobilidade reduzida para definir o grupo social com problemas de acesso e utilização dos ambientes construídos. Essa denominação inclui pessoas com deficiência, crianças, idosos, pessoas carregando pacotes, empurrando carrinhos de bebê, carrinhos de compra e aquelas que estão com alguma lesão temporária. (CAMBIAGHI 2007, p.44)

A cidade, sendo o local responsável pela promoção da inclusão, deve oferecer condições de acesso a todos os cidadãos, independente de suas restrições. "A cidade produz e reproduz a exclusão social, quando não facilita a mobilidade plena no ir e vir da cidade, impedindo o real sentido da palavra cidadania. "Massari (2009). Para Papanek (1997, p.236), “todos nós estamos envolvidos no design. Como

1 Regras proporcionais definidas por Vitrúvio em seus dez livros da arquitetura. É o modelo ideal para o ser humano, cujas proporções são perfeitas, segundo o ideal clássico da beleza. Disponível em http://leonardodavinci.stanford.edu/submissions/clabaugh/today/perfectman.html Acessado em: 17/08/2010 
utilizadores, somos tanto consumidores como vítimas do ambiente, dos edifícios, dos utensílios e artefactos [sic] que constituem o nosso mundo."

A acessibilidade no Brasil tem alcançado uma visibilidade crescente nos últimos anos devido ao surgimento de leis, decretos e normas técnicas que afirmam o direito de acesso igualitário, ou seja, a acessibilidade à todos. 0 tema evidenciou-se a partir da institucionalização pela ONU do ano internacional das pessoas deficientes e do programa de ação mundial para pessoas com deficiência. Além disso, graças às mudanças que vêm ocorrendo na pirâmide etária, onde se percebe 0 aumento do número de idosos, novas medidas foram tomadas em relação à inclusão de minorias à sociedade.

Apesar de o DU ter ingressado no Brasil na década de 80, é somente na década de 90 que passa a ser conhecido, ampliando os conceitos da acessibilidade, antes vistos exclusivamente nas normas técnicas. Para Dischinger a Mattos (2002), o Design Universal não é uma tendência de projeto, mas uma postura fundamental para promover a acessibilidade de todos os usuários.

Desenho Universal é a concepção de produtos e ambientes para serem utilizados por todas as pessoas, na maior medida do possivel, sem a necessidade de adaptação ou desenho especializado. (MACE, 2010).

Dessa forma, os princípios do Design Universal serão inseridos gradualmente no desenvolvimento de novos projetos a partir do momento em que a diversidade humana for respeitada. "A indústria e os designers parecem mesmo se esquecer de que o usuário desses produtos é o homem." (MORAES, 1997, p.106). Adequar ambientes, produtos e serviços às reais necessidades das pessoas é essencial, pois só assim as barreiras da inclusão serão erradicadas aos poucos.

No campo da arquitetura existem normas, como a NBR 9050:2004², que auxilia na obrigatoriedade da inserção da acessibilidade no projeto. Mas, ao se falar em produtos e serviços acessíveis, o contexto se torna incerto, pois, ainda são muitas as perguntas a serem levantadas, e dúvidas de como serão aplicados na prática esses princípios teóricos.

Por fim, será que existe um desconhecimento ou falta de interesse por parte dos estudantes e profissionais sobre essa temática? Ou Será uma falha na formação acadêmica, que não aborda o assunto sob uma ótica importante e aplicável?

2 Acessibilidade a edificações, mobiliário, espaços e equipamentos urbanos. Disponível em http://www.mpdft.gov.br/sicorde Acessado em 01/08/2011. 


\section{A Trajetória do Design Universal}

0 debate pelos direitos humanos pós II Guerra Mundial se intensificou, trazendo uma nova visão em diversas áreas do conhecimento, inclusive no design. "Nos anos 60, os designers começaram a considerar ativamente as implicações mais abrangentes do design para sociedade." (COOPER, 2005). Foi nesse cenário, que o Japão, os Estados Unidos e as nações europeias se reuniram em 1961 na Suécia para uma conferência que deu início dois anos depois - 1963 - a Barrier - Free Design ou Projeto Livre de Barreiras, "uma comissão com o objetivo de discutir desenhos de equipamentos, edifícios e áreas urbanas adequados à utilização por pessoas com deficiência ou com mobilidade reduzida." (CARLETTO; CAMBIACHI, 2008, p. 8).

o conceito de desenho livre de barreiras acabou evoluindo para o de desenho universal, adotado inicialmente nos Estados Unidos. Universal por se destinar a qualquer pessoa e por ser fundamental para tornar possível a realização das ações essenciais praticadas na vida cotidiana, o que na verdade é uma consolidação dos pressupostos dos direitos humanos. (CAMBIAGHI, 2007, p. 16)

Ao se pensar a necessidade de projetar o espaço para todos, e não diferenciá-lo para pessoas com deficiência ou incapacidade, o Design Universal insere uma nova visão para a concepção da inclusão. “Design é uma questão social porque é um mau projeto que converte uma limitação em uma deficiência. Possuir pouca mobilidade no pulso só se torna uma incapacidade quando os controles são muito pequenos." (FERRÉS, 2005). De acordo com Preiser (2008, apud PRAD0; LOPES; ORNSTEIN, 2010 p.20), "0 desenho universal se auto denominou como um potente fator para melhoria da qualidade de vida de todas as pessoas, em bases globais."

o desenho universal não é uma tecnologia direcionada apenas aos que dele necessitam, é para todas as pessoas. A ideia do D.U é evitar a necessidade de ambientes e produtos especiais para pessoas com deficiência, no sentido de assegurar que todos possam utilizar todos os componentes do ambiente e todos os produtos. Há quatro princípios básicos do desenho universal: o primeiro é acomodar uma grande gama antropométrica, $e$ isto significa acomodar pessoas de diferentes dimensões: altas, baixas, em pé, sentadas etc.; o segundo princípio é reduzir a quantidade de energia necessária para utilizar os produtos e o meio ambiente; o terceiro é tornar o ambiente e os produtos mais abrangentes e o quarto princípio é a ideia do desenho de sistemas, no sentido de pensar em produtos e ambientes como sistemas, que talvez tenham peças intercambiáveis ou a possibilidade de acrescentar características para as pessoas que têm necessidades especiais. (EDWARD STEINFELD, 1994) 
Esse conceito, apresentado acima, foi incorporado ao texto da NBR 9050:1994 atualmente substituída pela NBR 9050:2004 - que estava sendo finalizada na época. Sendo assim, a trajetória do Design Universal foi traçada por lutas sociais, e constantes movimentações por uma melhoria na qualidade de vida de grupos excluídos. Os conceitos vêm sendo ampliados e discutidos durante esses anos, mas na prática ainda são pouco aplicados. É necessário que os ambientes e produtos, principalmente aqueles utilizados por todos, sejam pensados para diferentes usuários, com distintas limitações. Assim, começa a construção de uma sociedade mais inclusiva na prática.

0 aumento da faixa etária da população é uma realidade, o último Censo de 2010 demonstrou que 0 país caminha velozmente rumo a um perfil demográfico cada vez mais envelhecido. Esse fator transforma as relações da sociedade, que passa a ter novas demandas, ainda pouco supridas, principalmente em relação a produtos mais acessíveis a esse público - idosos. Porém, quando um produto é desenvolvido para suprir ou reduzir uma deficiência específica ele é denominado uma tecnologia assistiva.

Tecnologia assistiva é uma área do conhecimento, de característica interdisciplinar, que engloba produtos, recursos, metodologias, estratégias, práticas e serviços que objetivam promover a funcionalidade, relacionada à atividade e participação, de pessoas com deficiência, incapacidades ou mobilidade reduzida, visando sua autonomia, independência, qualidade de vida e inclusão social. (CORDE - Comitê de Ajudas Técnicas - ATA VII)

A tecnologia assistiva é utilizada para identificar todos os produtos e recursos que contribuem de alguma maneira para ampliar as habilidades funcionais de pessoas com deficiência; e, tem por objetivo promover uma vida mais independente, portanto, é um conceito que está atrelado ao DU. Eventualmente, será preciso inserir uma tecnologia assitiva a um ambiente ou produto, para que possibite a sua utilização por um número maior de pessoas.

Portanto, para que ocorra a inserção da teoria na prática, foram criados princípios que auxiliam em transformar importantes propriedades do DU em requisitos de projeto, auxiliando no desenvolvimento de novos produtos e na avaliação dos já desenvolvidos.

\section{Os princípios do Design Universal}

De acordo com o Center for Universal Design - College of Design da Universidade Estadual da Carolina do Norte, existem sete princípios que podem ser empregados para orientar as futuras práticas projetuais de profissionais do campo da arquitetura e do design, e também para fazer uma avaliação de produtos já no mercado. São eles: uso equitativo, uso flexível, uso simples e intuitivo, informação de fácil percepção, tolerância ao erro, baixo esforço físico, dimensão e espaço para aproximação e uso. 


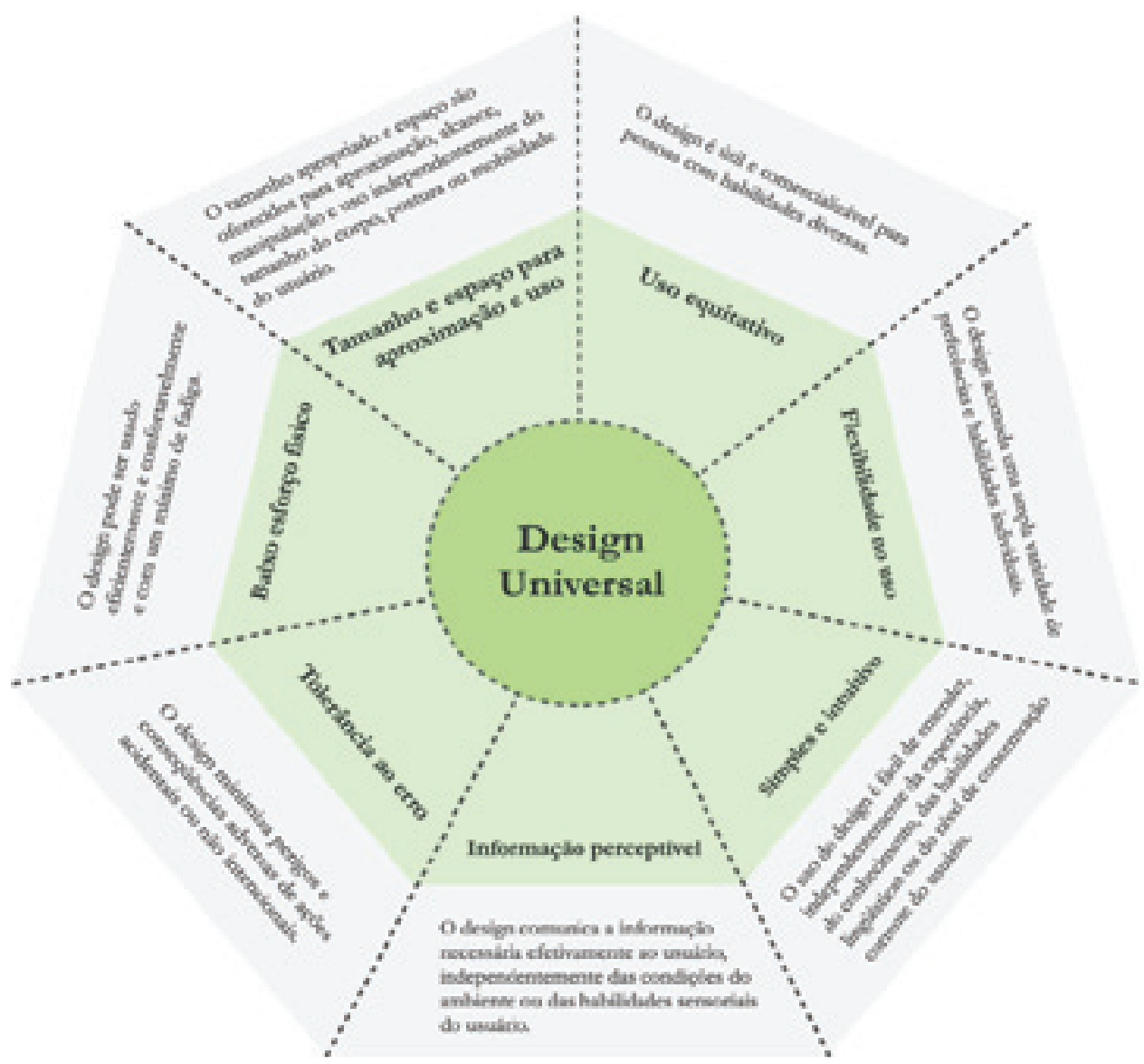

Fig. 1 - Ilustração representativa dos sete princípios projetuais do Design Universal.

Fonte: Ilustração desenvolvida pela autora com base nos princípios do Center for Universal Design - College of Design da Universidade Estadual da Carolina do Norte.

A ilustração gráfica desenvolvida busca representar os sete princípios projetuais do Design Universal de modo igualitário, indicando que é possível alcançar o Design Universal por meio da aplicação de um ou mais princípios. Isso dependerá do objetivo e das características do projeto. Dessa forma, cada princípio será melhor explanado, e exemplificado por meio de imagem.

\section{Princípio 1 - Uso equitativo}

0 design não pode estigmatizar ou colocar em desvantagem nenhum grupo de usuários. 0 desenho universal não é elaborado para um grupo específico, mas sim, para todos.

Para ter o uso equitativo, deve-se: propiciar os mesmos recursos de uso para todos, eliminar uma possível segregação e estigmatização, promover o uso com privacidade, segurança e conforto; sem deixar de ser um produto atraente. 


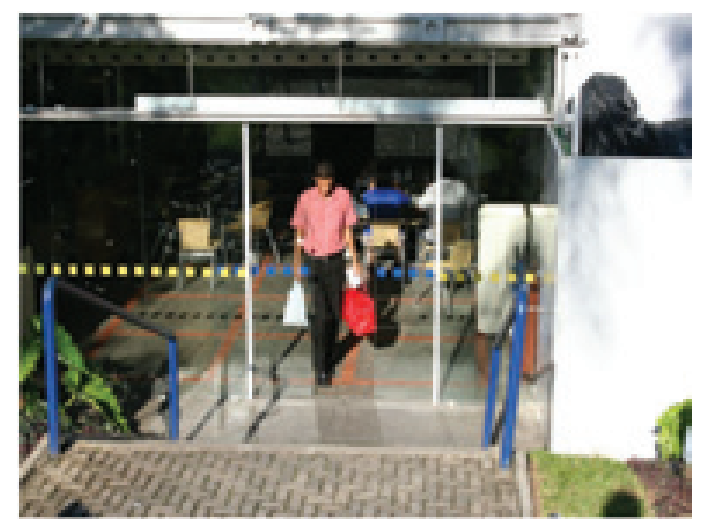

Fig. 2 - Porta automática. Fonte: http:// www.inndoor.net

\section{Princípio 2 - Uso flexível}

0 design acomoda a mais ampla série de preferências e habilidades individuais. Para tal, devem-se oferecer diferentes maneiras de utilização, possibilitar o uso para destros e canhotos, facilitar a precisão e destreza do usuário e possibilitar 0 uso por pessoas com diferentes tempos de reação a estímulos.

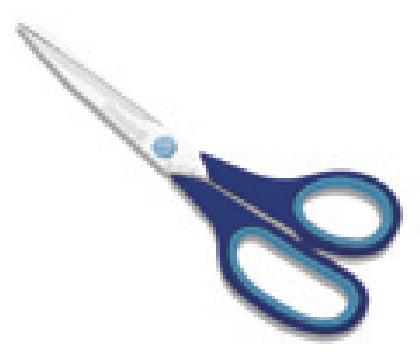

Fig. 3 - Tesoura para destros e canhotos. Fonte: http://www.eberlesolution.com.br

\section{Princípio 3 - Uso simples e intuitivo}

0 design é facilmente compreendido para o uso, respeitando a experiência dos usuários, conhecimento, idioma ou nível de concentração. Para tanto, deve: eliminar possíveis complexidades desnecessárias, acomodar uma ampla gama de habilidades linguísticas do usuário e disponibilizar informações facilmente perceptíveis em ordem de importância.

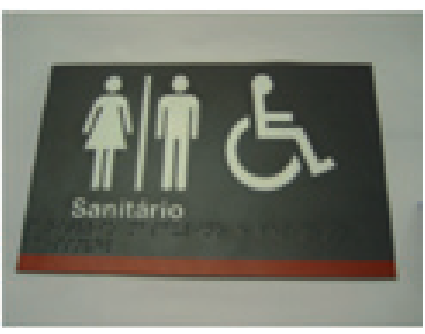

Fig 4. - Sinalização de banheiro com ilustração, texto e com linguagem em braille.

Fonte: http://sinalizacaobraille.com 


\section{Princípio 4 - Informação de fácil percepção}

0 design comunica necessariamente informações efetivas aos usuários, com respeito às condições do ambiente ou às suas habilidades sensoriais. Essas informações devem apresentar diferentes linguagens sensoriais - visuais, verbais, táteis - fazendo com que a legibilidade da informação seja maximizada, sendo percebida por pessoas com diferentes habilidades e deficiências - cegos, surdos, analfabetos, entre outros.

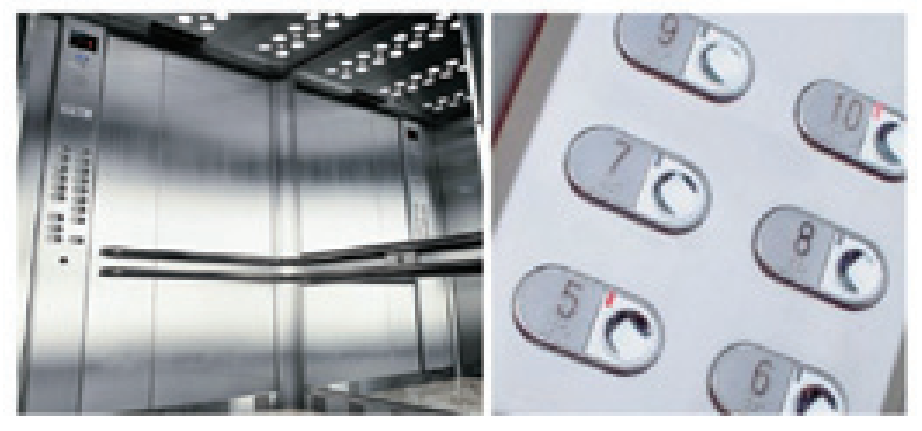

Fig. 5 - Elevador com painel de comando com código braille, aviso visual e sonoro. Fonte http://www.thyssenkruppelevadores.com.br

\section{Princípio 5 - Tolerância ao erro}

0 design minimiza o perigo e as consequências adversas de uma ação acidental ou semintencionalidade. Para tal, devem-se agrupar os elementos que apresentam risco, isolando-os ou eliminando-os, empregar avisos de risco ou erro, fornecer opções de minimizar as falhas, e evitar ações inconscientes em tarefas que requeiram vigilância.

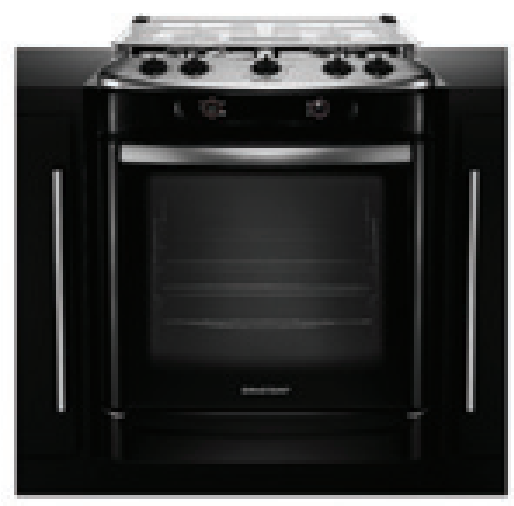

Fig. 6 - Fogão inteligente, os botões e a porta do forno vêm com trava de segurança e alerta sonoro.

Fonte: http://www.brastemp.com.br 


\section{Princípio 6 - Baixo esforço físico}

0 design pode ser utilizado de forma eficiente, confortável e com o mínimo de fadiga. Para alcançar esse princípio deve-se: possibilitar que os usuários mantenham o corpo em posição confortável, usar força de operação razoável, minimizar ações repetidas, e diminuir a sustentação do esforço físico.

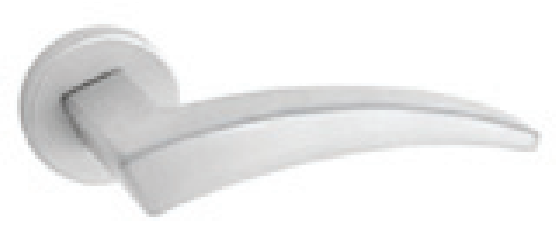

Fig. 7 - Maçaneta do tipo alavanca

Fonte: http://www.lockwell.com.br/

\section{Princípio 7 - Dimensão e espaço para aproximação e uso}

0 tamanho e o espaço deverão ser apropriados para aproximação, toque, manipulação e uso de acordo com o tamanho do corpo do usuário. A postura ou mobilidade devem ser levados em consideração. É necessário que se implante sinalização em elementos importantes e, que se tornem confortavelmente alcançáveis todos os componentes para os usuários sentados ou em pé, acomodando variações de mãos e empunhadura. E, por último, que se implantem espaços adequados para uso de tecnologias assistivas.
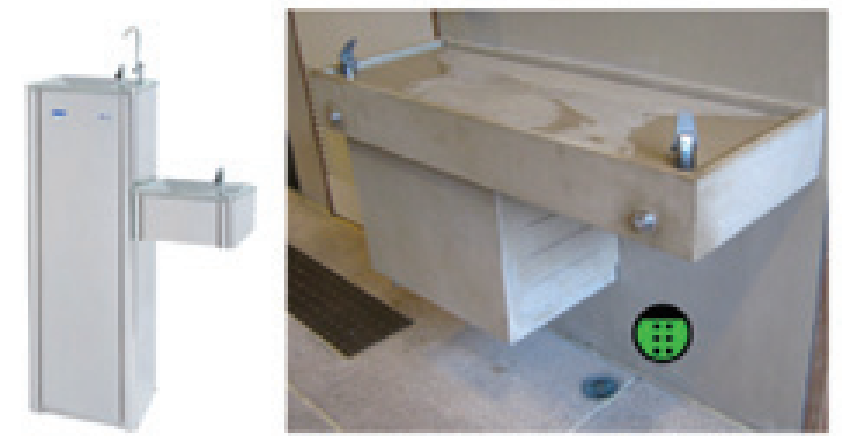

Fig. 8 - Bebedouro com diferentes alturas e bebedouro com espaço para cadeira de rodas. Fontes: http://www.casadosbebedouros.com.br e http://thaisfrota.wordpress.com 
Os exemplos citados acima retratam os benefícios da aplicação dos princípios do DU, uma vez que este proporciona o uso de ambientes e objetos por um número maior de usuários. Isso demonstra que esses projetos facilitam proporcionalmente a vida para todos os usuários, além, e principalmente de certos grupos específicos - deficientes, idosos, crianças, entre outros-. Contudo, é necessário enfatizar que os demais aspectos considerados no desenvolvimento de produtos devem continuar a ser considerados. Para Ferrés (2005), o DU “não entra em conflito com nenhum outro princípio de Good Design, como por exemplo, fazer com que o produto seja desejável." Assim, o Design Universal propõe a aplicação de princípios que são capazes de ampliar as funcionalidades de um produto e reduzir as restrições dos usuários, possibilitando que um grupo maior de pessoas utilize esses objetos.

\section{A coleta de dados}

A pesquisa realizada foi de natureza exploratória, com "0 objetivo de proporcionar visão geral, de tipo aproximativo, acerca de determinado fato." (GIL, 1999, p.43). Para levantar uma reflexão sobre o Design Universal foi necessário realizar uma revisão bibliográfica através de livros, periódicos, artigos e cartilhas sobre acessibilidade. Por meio desse material, foi construído o referencial teórico do trabalho, contextualizando-o junto ao design industrial, criando um paralelo das escolas de design e dos movimentos artísticos que influenciaram essa temática voltada ao design com um cunho mais social.

Após a explanação da base teórica do trabalho, ocorreu o levantamento de dados por meio de uma pesquisa aplicada com designers -estudantes e profissionais-, para atingir um dos objetivos do trabalho: levantar o nível de entendimento dos estudantes e profissionais sobre a temática.

A pesquisa buscou ter noção do conhecimento e da relevância que esse tema tem entre estudantes e profissionais no Brasil, através da técnica do levantamento (survey), que pode ser definido como "método para coletar informação de pessoas acerca de suas ideias, dados, sentimentos, planos, crenças, bem como origem social, educacional e financeira." Fink ¿ Kosecoff (1985, apud GÜNTHER, 2003, p. 1). 0 instrumento utilizado para coleta de dados foi o questionário, desenvolvido em uma ferramenta ${ }^{3}$ gratuita online, cujos resultados são visualizados diretamente no software Excel; sendo sua aplicação feita através do endereçamento do link via e-mail. Inicialmente, esse questionário foi enviado para 43 pessoas da área do design, distribuídas pelas 5 regiões geográficas brasileiras. Posteriormente, essas pessoas encaminharam esse questionário para estudantes, profissionais, universidades e empresas, atingindo um total de 652 respostas durante os 15 dias em que estava online.

3 Google Forms. Disponível em http://www.google.com/google-d-s/forms/ 
0 questionário foi estruturado em duas partes: a primeira parte contendo um total 9 perguntas gerais sobre 0 conhecimento do respondente sobre 0 tema, e a segunda parte com 8 perguntas pessoais. A primeira parte era composta por perguntas sobre acessibilidade em geral - com foco na cidade -, e finalizava com as demais sobre Design Universal em específico. Todas as perguntas eram seguidas de alternativas para o respondente marcar a resposta que melhor se adequava, convertendo em resultados mais quantificáveis e lógicos.
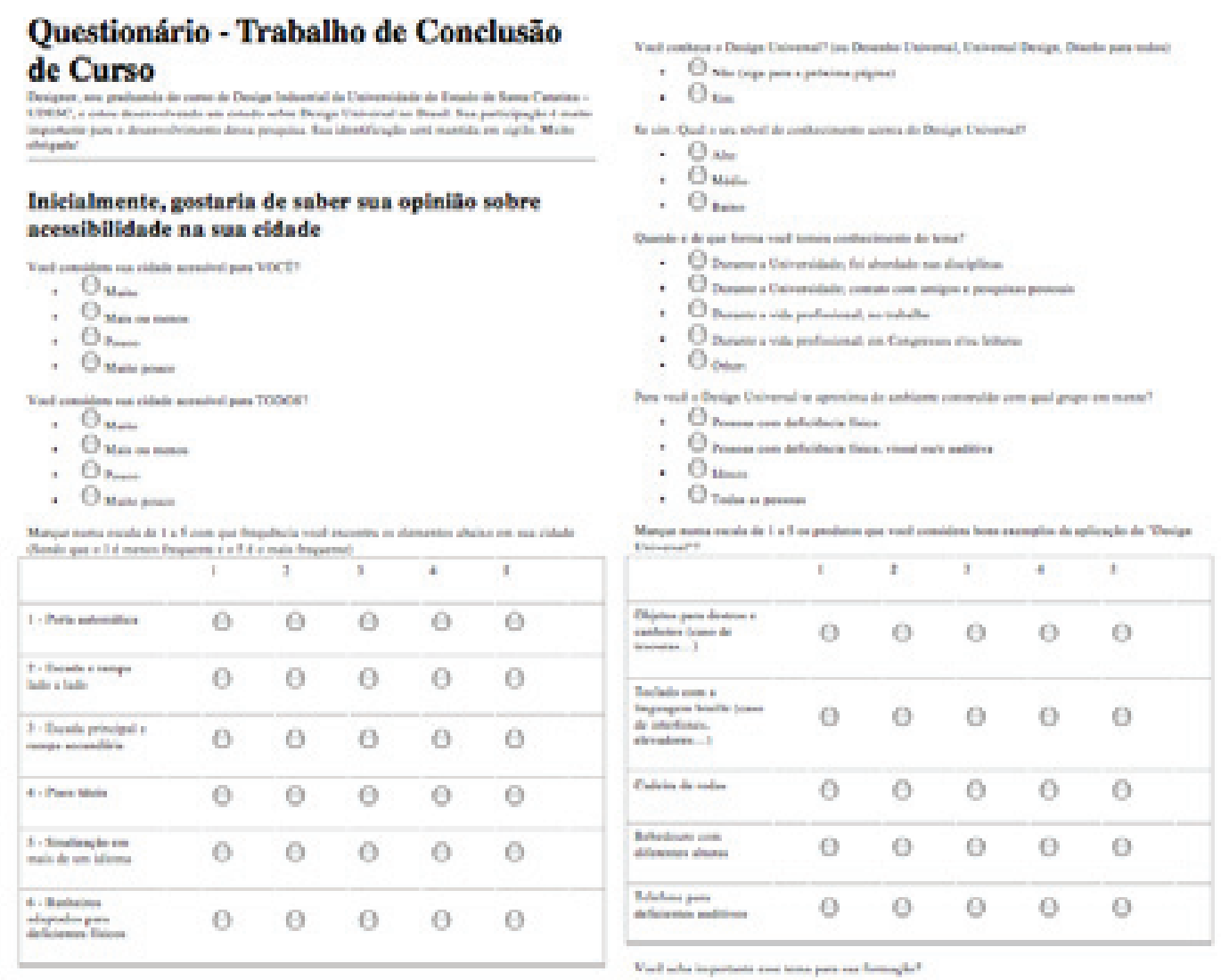

Fig. 9 - Primeira parte do questionário Fonte: A autora

Na segunda parte, foram abordadas as informações pessoais dos respondentes sexo, região onde reside, instituição de ensino, curso, fase - e três perguntas, que estão descritas abaixo.

Você já morou em outro país? Essa pergunta foi importante para mais tarde cruzar dados e fazer novos questionamentos, como, se o nível de conhecimento sobre 0 tema aumentava nas pessoas que já moraram em países da Europa, por exemplo.

Você possui algum tipo de deficiência? Essa pergunta só constava duas respostas - não ou sim- buscando, assim, de forma objetiva, levantar quantas pessoas se consideravam deficientes. Sendo importante para comparar com a última pergunta 
do questionário e analisar quantas pessoas utilizam uma tecnologia assitiva, mas não se consideram com alguma restrição ou deficiência.

No momento você utiliza algum dos itens abaixo? Para essa última pergunta havia as possíveis respostas: óculos de grau, muletas, próteses, aparelho auditivo e cadeira de rodas.

Logo, a primeira parte do questionário foi desenvolvida com o objetivo de levantar o conhecimento dos respondentes sobre o assunto, que era o objetivo principal. Já a segunda parte foi elaborada a fim de alcançar uma maior percepção o público pesquisado, para poder dar um maior subsídio à pesquisa, delimitando a população por regiões geográficas, universidades - públicas ou privadas-, fases da graduação- inicial, intermediária ou final - e, assim, acrescendo a pesquisa de maiores dados para classificação e cruzamento das respostas nos resultado finais.

\section{Os resultados obtidos}

A partir da análise dos dados obtidos, foi possível montar um panorama do Design Universal no Brasil. Cada pergunta foi transformada em um gráfico para uma melhor visualização das respostas, sendo, posteriormente, criados outros gráficos cruzando duas ou mais perguntas, quando geravam reflexões interessantes de serem analisadas em conjunto.

A primeira análise executada foi a da população da pesquisa: das 652 pessoas que responderam a pesquisa, a maioria são da regiões sul (331) e sudeste (210); houve uma pequena participação de outras regiões - nordeste (81) norte (22), e centro-0este (8) -; a maioria dos estudantes são de universidades públicas (477); do curso de design gráfico (315) e design de produto (272); de fase inicial (88), fase intermediária (213); fase final (170); formados (120); pós graduados (61). Assim, pode-se constatar um predomínio de estudantes (471). Contudo, a pesquisa contou, também, com uma participação significativa de profissionais (181). Após esse primeiro levantamento numérico generalizado da população, e caracterização do público que respondeu o questionário, foram realizados gráficos relacionando os resultados. Serão apresentados neste trabalho uma amostra dos gráficos que foram gerados com a pesquisa e uma reflexão dos resultados obtidos com esses dados. 


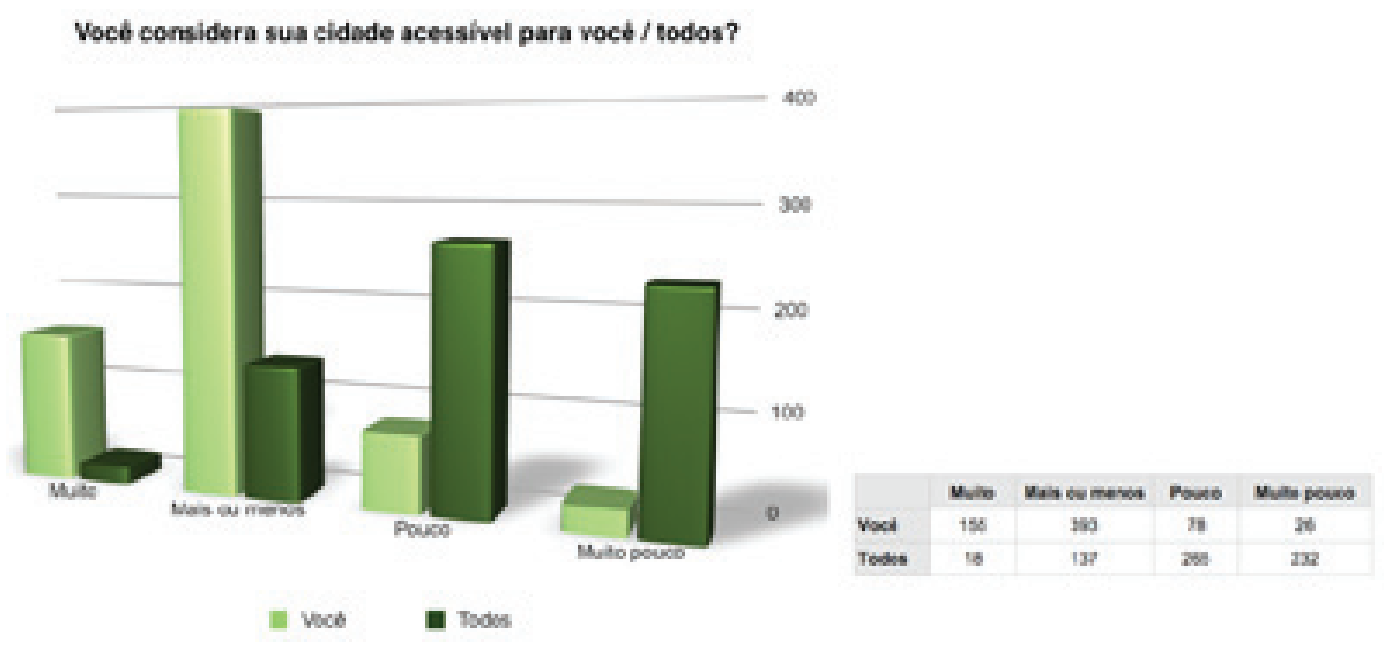

Fig. 10 - Gráfico cruzando as duas primeiras perguntas Fonte: A autora

A primeira e segunda pergunta do questionário era em relação à acessibilidade na cidade: se esta era vista de uma determinada maneira quando era para o próprio respondente e de outra, quando questionado para todas as pessoas. Os resultados indicaram que a cidade é vista de formas diferentes, quando os respondentes são jovens - não foi perguntado a faixa etária no questionário, mas pela quantidade de estudantes é possível encarar a maioria dos respondentes como jovens - e mais aptos a desenvolver diversas atividades com precisão e agilidade. Para esses, a cidade é vista como acessível. Contudo, ao se pensar em pessoas com deficiência, mobilidade reduzida ou idosos, a cidade se torna pouco acessível. Assim, seria interessante encarar a acessibilidade de uma forma geral, a acessibilidade é para todas as pessoas e deveria ser vista do mesmo modo por diferentes pessoas.

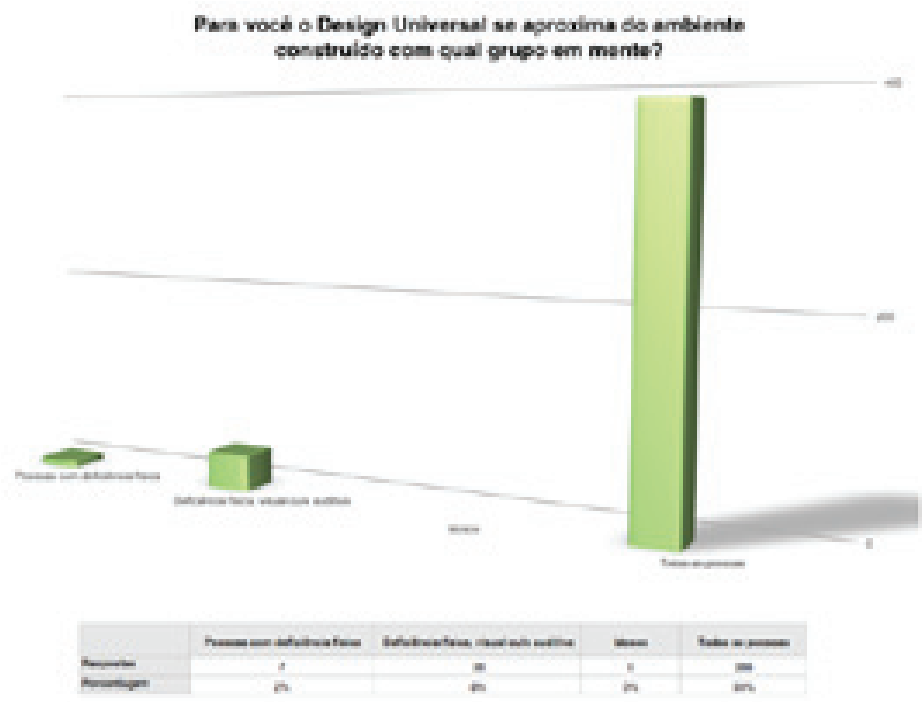

Fig. 11 - Gráfico da 7 š pergunta da primeira parte do questionário Fonte: A autora 
0 gráfico acima só foi respondido pelas pessoas que assinalaram a alternativa sim na quarta pergunta - Você conhece o Design Universal? (ou Desenho Universal, Universal Design, Diseño para todos) -, as pessoas que disseram não conhecer o DU foram encaminhadas para a segunda parte do questionário. A intenção foi filtrar as pessoas que de fato não conheciam, ou nunca ouviram falar em Design Universal. A partir dessa triagem, observa-se que 221 pessoas, ou seja, 34\% dos respondentes não tem o menor conhecimento sobre o tema. As pessoas que responderam sim, ou seja, que disseram conhecer o DU, prosseguiram para mais quatro perguntas, sendo a fig.11, uma delas. Para você o Design Universal se aproxima do ambiente construído com qual grupo em mente? Essa pergunta buscou compreender como o Design é visto, se de fato ele é associado às pessoas com deficiência ou é entendido para todas as pessoas. A resposta foi satisfatória, a maioria dos designers associam o DU à todas as pessoas, somente $10 \%$ assinalou as outras opções.
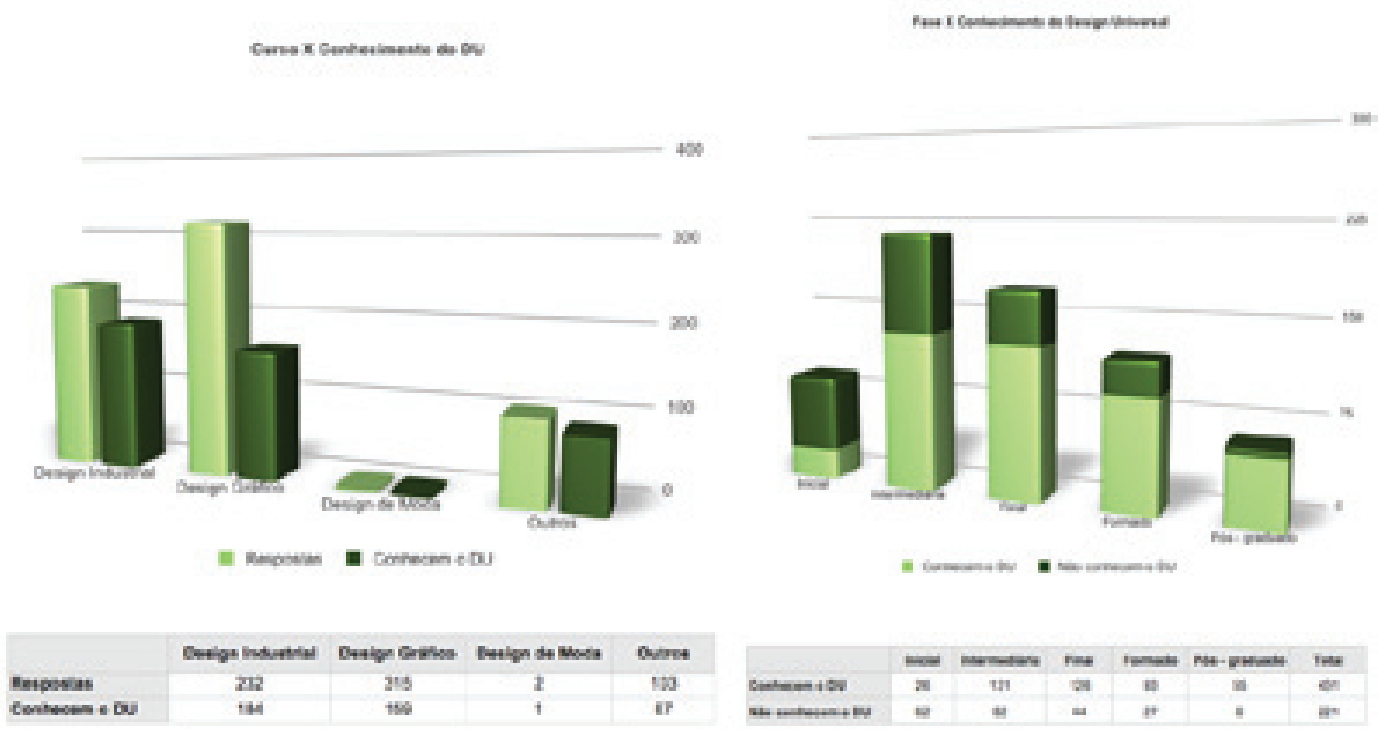

Fig. 12 - Gráficos Curso e fase $x$ conhecimento Fonte: A autora

Ao se observar o conhecimento pelo curso e pela fase, o maior nível de conhecimento é dos designers industriais, dos 232 respondentes, 184 disseram conhecer o DU. Já os designers gráficos, somente 159 dos 315 conhecem. Quando o conhecimento foi comparado por fase, percebe-se que é crescente de acordo com o tempo de curso. As fases finais, os formados e pós graduados tiveram mais contato com o tema. 

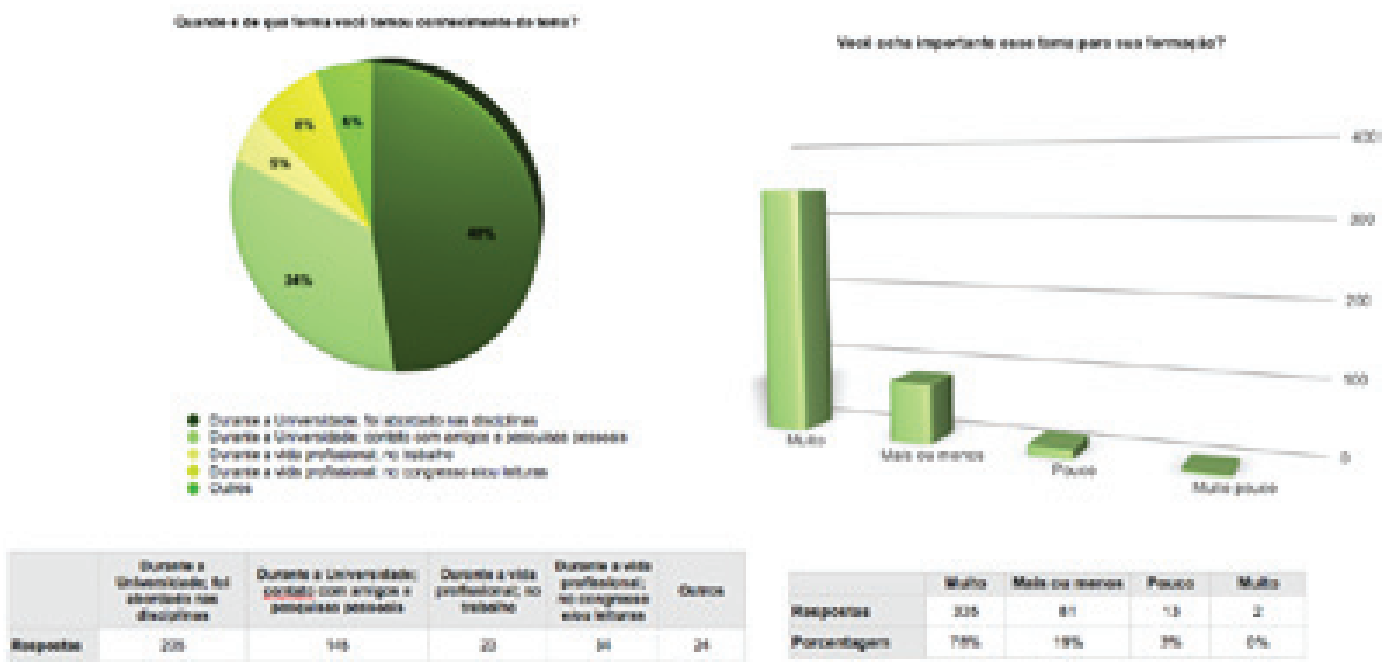

Fig. 13 - Gráficos de como tomou conhecimento pelo tem e a importância na formação.

Fonte: A autora

Muitas das informações levantadas já são suficientes para refletir diversas questões, mas um dos objetivos do trabalho era compreender de que forma esse conhecimento é repassado aos designers. A maioria dos designers revelaram tomar conhecimento pela temática ainda durante a universidade - principalmente nas disciplinas. Esse é um dado importante, já que demonstra o interesse dos professores em levar novas temáticas para a sala de aula. Vale ressaltar também a importância de congressos e eventos na disseminação do conhecimento.

Ao serem questionados sobre a importância desse tema para a formação, a maioria (78\%) avalia esse tema como muito importante. Mas uma significativa parcela de $19 \%$ acredita que é mais ou menos importante, e somente uma minoria vê esse tema com pouca importância, isso indica que existe um interesse crescente pela temática.

Logo, os resultados e as reflexões foram importantes para entender o contexto em que o DU se encontra no Brasil, percebe-se que existe um interesse por parte dos estudantes, e que o tema está começando a despertar atenção dentro das universidades. Porém, ainda é alarmante encarar dados como os $44 \%$ - soma dos que responderam não conhecer o DU e as pessoas que se equivocaram nas perguntas específicas do DU- dos entrevistados que de fato não sabiam o que era Design Universal, ou tinham uma ideia errônea do tema.

\section{Considerações finais}

Observa-se que a maioria dos ambientes e produtos utilizados diariamente não amenizam as restrições das pessoas com deficiência ou mobilidade reduzida. Através da adoção e aplicação dos sete princípios do DU é possível desenvolver pro- 
dutos que buscam uma melhor interação com os usuários, permitindo que mais pessoas 0 utilizem, independentemente de suas habilidades e restrições. 0 conceito do DU é novo e consequentemente frágil, necessitando ainda ser entendido e absorvido por pessoas que trabalham nas áreas ligadas à arquitetura e design, para então a teoria ser colocada em prática.

0 presente artigo buscou contribuir com dados atualizados do Design Universal no Brasil, através de uma pesquisa com um número relativamente alto de estudantes e profissionais foi possível aprofundar resultados úteis sobre o DU, mas não somente isso, também conseguiu fazer o respondente pensar sobre Design Universal, indo ao encontro do objetivo geral deste trabalho, que é a discussão do Design Universal. Sendo assim, existe a necessidade de se criar práticas para a inclusão deste assunto nas universidades, fortalecendo o entendimento dos conceitos e a sua correta aplicação.

Por fim, espera-se futuras pesquisas na área, baseadas principalmente na prática. A aplicação dos princípios do Design Universal e avaliações dos benefícios gerados, assim como estudos voltados às pessoas com deficiência, com mobilidade reduzida e idosos, visando ampliar as percepções para a aplicação do DU. Ao se trabalhar com usuários extremos, as exigências são maiores, e quando se consegue atender adequadamente a esse público, certamente atenderá a vários outros, ou seja, proporcionará o uso de um mesmo produto por pessoas com diferentes habilidades. 


\section{Referências Bibliográficas}

> CAMBIAGHI, Silvana. Desenho Universal: métodos e técnicas para arquitetos e urbanistas. São Paulo: SENAC, 2007.

> CARLETTO; Ana Claudia; CAMBIAGHI, Silvana. Desenho Universal: Um conceito para todos, 2008. Disponível em: 〈http://www.maragabrilli.com.br/desenho- universal.html>23/Jun/2010.

> COOPER, R. Design e Responsabilidade Social. In: Revista Design em Foco, v. 2 nć. 2. Salvador: EDUNEB, 2005, p. 79-85. Jul/Dez 2005. Entrevista.

> CORDE - Coordenadoria Nacional para Integração da Pessoa Portadora de Deficiência. Comitê de Ajudas Técnicas, ATA VII. Disponível em: 〈http://www.mj.gov.br/ sedh/ct/corde/dpdh/corde/comite_at.asp> Acessado em: 21/Maio/2010.

> DISCHINGER, Marta; MATTOS, Melissa. Habitação Universal. Disponível em <http:/ www.ctc.ufsc.br/habuniversal> Acessado em 11/Set/2010.

> FERRÉS, M. Sofia Pérez, 2005. Design Inclusivo. Disponível em <http://styx.nied. unicamp.br:8080/todosnos/acessibilidade/textos/design_inclusivo.html.> Acessado em $23 / \mathrm{jul} / 2011$.

$>$ GIL, Antonio Carlos. Métodos e técnicas de pesquisa social. 5. ed. São Paulo: Atlas, 1999.

> GÜNTHER, H. (2003). Como elaborar um Questionário (Série: Planejamento de Pesquisa nas Ciências Sociais, Nć 01). Brasília, DF: UNB, Laboratório de Psicologia Ambiental, 2008.

> IBGE, Censo Demográfico 2000-2010. 〈http://www.ibge.gov.br/home/presidencia/ noticias/noticia_visualiza.php?id_noticia=1272> Acessado em 10 out. 2011.

> MACE, Ron. [About Universal Design] Disponível em: 〈http://www.ncsu.edu/ www/ncsu/design/sod5/cud/about_ud/about_ud.htm>Acessado em: 27/Jun/2010.

> MASSARI, Solange Aparecida. A Igualdade Começa pelo Planejamento da Cidade. Disponivel em <http://www.forumdaconstrucao.com.br/conteudo. php?a=32दCod=187> Acessado em 02/ago/2011.

> MORAES, Dijon De. Limites do design. São Paulo: Studio Nobel, 1997.

> PAPANEK, Victor. Arquitetura e design: ecologia e ética. Lisboa: Ed. 70, 1997.

> PRADO, A. R. A. (Org.); LOPES, M. E. (Org.); ORNSTEIN,Sheila Walbe (Org.) . Desenho Universal: caminhos da acessibilidade no Brasil. 1a ed. São Paulo: Annablume Editora, Comunicação Ltda, 2010.

> STEINFELD, Edward. Arquitetura através do desenho universal. In: Curso Básico sobre Acessibilidade ao Meio Físico e VI Seminário sobre Acessibilidade ao Meio Físico. Brasília: Corde, 1994. 
Thais de Carvalho Larcher Pinto, mestranda no programa de Pós-Graduação em Arquitetura e Urbanismo - PósARQ da Universidade Federal de Santa Catarina - UFSC. Bacharel em Design Industrial pela Universidade do Estado de Santa Catarina - UDESC

thaislarcher@gmail.com

Jorge Elias Dolzan, coordenador de Design - Estácio de Santa Catarina - FESSC. Mestre em Ciências da Linguagem - UNISUL. Especialista em Ensino de Artes Visuais - CEART - UDESC. Bacharel em Desenho Industrial - CEART - UDESC.

jorgedolzan@yahoo.com.br

Luiz Salomão Ribas Gomez, coordenador do Laboratório de Orientação Gráfica Organizacional - LOGO/Universidade Federal de Santa Catarina - UFSC. Doutor em Engenharia

salomao.gomez@ufsc.br 